\title{
Utilização de Xaropes para a Tosse em Idade Pediátrica
}

\section{Use of Cough Syrups in Children}

Pedro Flores ${ }^{1}$

Autor Correspondente: Pedro Flores [pedro.v.silva@jmellosaude.pt] Rua Mário Botas, 1998-018 Lisboa, Portugal

\section{RESUMO}

A tosse é um sintoma muito frequente na idade pediátrica e, como tal motivo frequente de consulta médica. De acordo com a duração, a tosse pode ser classificada como aguda, subaguda ou crónica. A avaliação clínica deve ser sistemática e racional, podendo ser admitida terapêutica empírica em situações de suspeita de infeção, asma brônquica, refluxo gastroesofágico ou rinorreia posterior. A terapêutica sintomática da tosse em crianças inclui antitússicos centrais e periféricos, demulcentes ou mucolíticos. A evidência científica para a sua utilização é escassa, podendo ser ponderada para aumentar o conforto de crianças acima dos dois anos, por períodos curtos, e integrada num plano de investigação e reavaliação médica adequada.

PALAVRAS-CHAVE: Antitússicos; Criança

\section{ABSTRACT}

Cough is a very frequent symptom is children, and a usual cause for medical appointment. According to its duration, cough can be classified as acute, subacute or chronic. Patients must be evaluated systematic and rationally. Empirical therapy can be considered in suspected infections, asthma, gastro-oesophageal reflux and posterior rhinorrhoea. Symptomatic therapy in children includes central or peripheral antitussives, demulcents and mucolytics. Scientific evidence for their use is very scarce, but they can be considered to ameliorate comfort in children older than two years-old, for short periods, and integrated in an investigation and medical revaluation plan.

KEYWORDS: Antitussive Agents; Child 


\section{INTRODUÇÃO}

A tosse é um reflexo fisiológico complexo cuja finalidade é proteger as vias aéreas, eliminando material estranho e secreções, ou contrariando o broncospasmo. Os recetores deste arco reflexo localizam-se ao longo das vias respiratórias, da laringe até aos brônquios segmentares, bem como no tímpano, canal auditivo externo, diafragma, pleura, pericárdio e estômago. A estimulação destes recetores pode surgir por irritação química, estimulação tátil e forças mecânicas. A via aferente (ramos do nervo vago e laríngeo) leva o impulso até uma área mal definida do tronco cerebral, onde pode sofrer modulação cortical. Do tronco emerge a via eferente, que se dirige aos músculos respiratórios, desencadeando um movimento inspiratório profundo, seguido de encerramento da glote e subsequente abertura numa expiração súbita e explosiva. ${ }^{1,2}$

Na ausência de doença, é considerado normal que uma criança tussa cerca de 8 a 10 vezes por dia, sendo referidos como normais valores até 30 a 150 episódios de tosse nas 24 horas., ${ }^{3,4} \mathrm{O}$ reflexo da tosse pode ser inibido por supressores do centro reflexo (sedativos, narcóticos), bloqueio dos recetores (aspiração crónica), diminuição da força muscular (doenças neuromusculares) ou disfunção glótica (paralisia das cordas vocais, entubação traqueal ou traqueostomia, broncomalácia ou traqueomalácia).2.5 A ausência de tosse é um problema consideravelmente grave, que pode levar a fenómenos de aspiração e acumulação de secreções, com complicações pulmonares importantes. $2,5,6$

A tosse é, isoladamente, na idade pediátrica, motivo de atendimento médico em 10\% a 15\% das situações de consulta ou urgência..$^{5-7}$ Na maioria dos casos, é um sintoma agudo e autolimitado, com duração inferior a uma semana. No entanto, pode associar-se a sinais de gravidade (aspiração, asfixia, vómito ou síncope) ou ser, pela sua intensidade e duração, motivo de preocupação e de compromisso da qualidade de vida da criança e da família.7.8

A atitude diagnóstica e terapêutica em relação à tosse em idade pediátrica deve ser tomada de acordo com orientações adequadas, diferentes das do adulto. Nos últimos anos foram publicadas normas americanas, ${ }^{9-11}$ britânicas, ${ }^{12}$ australianas/neo-zelandezas, ${ }^{13}$ espanholas ${ }^{6}$ e portuguesas ${ }^{14}$ onde se sistematiza a evidência científica disponível.

Neste artigo temos como objetivo rever e atualizar procedimentos acerca da avaliação clínica, diagnóstico e tratamento da tosse na criança.

\section{AVALIAÇÃO}

A etiologia da tosse varia com a idade. Podem coexistir várias causas, pelo que é necessária uma abordagem integral deste sintoma. Uma primeira abordagem da tosse em pediatria pode ser a sua classificação em função do tempo de duração: aguda, subaguda, crónica e recorrente. $5,6,9-14$

\section{TOSSE AGUDA}

As normas americana e australiana definem-na como tendo duração inferior a 2 semanas. ${ }^{9,10,11,13} \mathrm{Na}$ norma britânica, ${ }^{12}$ considera-se que a tosse aguda tem uma duração inferior a 4 semanas. A causa mais frequente é a rinofaringite viral, que tem resolução habitualmente espontânea, num intervalo mais ou menos prolongado. $\mathrm{Na}$ idade pré-escolar podem ocorrer, a cada ano, 8 a 10 episódios de infeção respiratória superior. Mais raramente, a tosse aguda pode ser causada por pneumonia ou aspiração de corpo estranho.,9

A tosse aguda em idade pediátrica, na criança previamente saudável e sem evidência clínica de complicação, não necessita em geral de exames auxiliares de diagnóstico uma vez que é habitualmente autolimitada. Algumas características clínicas podem apontar para outros diagnósticos: sibilância pode sugerir crise de asma; tonalidade estridulosa ou metálica na laringite; paroxismos na síndrome coqueluchoide; em staccato na infeção por Chlamydia ou Mycoplasma, entre outras. $6,10,13,15$

Uma radiografia do tórax pode estar indicada na suspeita clínica de pneumonia, ou se a tosse tiver início súbito após engasgamento (caso em que, se possível, a radiografia deve ser feita em inspiração e expiração). Se a criança tiver antecedentes de patologia respiratória crónica, pode ser útil a realização de outros exames. ${ }^{16-19}$

A terapêutica deve ser etiológica. O alívio sintomático inclui hidratação adequada e aspiração de secreções. Não há atualmente evidência, na tosse aguda, que justifique a utilização de antitússicos, anti-histamínicos e / ou combinações entre eles. ${ }^{6,10,15,19,20}$ Os efeitos secundários destes fármacos podem potencialmente ser graves. ${ }^{20}$

A educação dos pais, população e pessoal de saúde em relação à história natural da tosse aguda associada a infeções das vias aéreas superiores é fundamental para evitar consultas, exames e medicamentos desnecessários. ${ }^{6,16-22}$

\section{TOSSE SUBAGUDA}

Entre as definições de tosse aguda e crónica há um período de tosse designada de subaguda, que os autores 
americanos e australianos definem como de 2 a 4 semanas ${ }^{9-11,13}$ e os britânicos de 4 a 8 semanas. ${ }^{12}$ A etiologia infeciosa mantém-se como a mais provável (infeção viral das vias aéreas superiores, infeção bacteriana ou mista).

Nestes casos está habitualmente indicada a realização de radiografia do tórax. Se esta for normal, a criança deve ser reavaliada clinicamente às 8 semanas. Se mantiver tosse após esse tempo, deve iniciar-se avaliação de tosse crónica. ${ }^{23-28}$

\section{TOSSE CRÓNICA}

Definida por duração superior a 4 semanas (EUA, Austrália) ou 8 semanas (Reino Unido). Nestes casos deve ser realizada uma investigação etiológica hierarquizada e criteriosa. ${ }^{6,9-13}$

Podemos dividir a tosse crónica em dois grupos:

- Específica: a clínica é sugestiva de diagnóstico específico, como, por exemplo, nos casos de asma, bronquiectasias, fibrose quística, aspiração de corpo estranho, síndromes aspirativas, infeções respiratórias atípicas, cardiopatias, patologia intersticial, entre outras (Tabela 1). ${ }^{23-28}$

- Inespecífica: engloba quadros que cursam com tosse como sintoma isolado, na ausência de sinais ou sintomas sugestivos de patologia num doente que se encontra bem, com radiografia do tórax normal e espirometria sem alterações. ${ }^{6} \mathrm{Na}$ maioria dos casos, a sintomatologia continua a ser devida a processos inflamatórios das vias aéreas superiores, na sequência de infeções virais de que o epitélio respiratório ainda não recuperou. Como tal, podem prolongar-se, mas não são graves e acabam por ter remissão espontânea. Pensa-se que a persistência da tosse se deva a maior sensibilidade de recetores a infeção viral, mas há que ter em conta sempre os fatores de contaminação ambiental e tabaco. ${ }^{23,25,27}$

Em geral, consegue-se chegar a um diagnóstico etiológico da tosse crónica através de uma avaliação clínica cuidadosa. A anamnese pode ser conclusiva em $80 \%$ dos doentes. $5,6,9,10$
O início e a forma de apresentação podem ser dados anamnésicos importantes: início agudo e após episódio de engasgamento na aspiração de corpo estranho; início nas primeiras semanas de vida (malformação das vias aéreas, fibrose quística, refluxo gastroesofágico, discinesia ciliar); desencadeada por fatores como o exercício físico, ar frio e riso na asma brônquica; agravada pelo decúbito ou refeições (refluxo gastroesofágico, sinusite ou hipertrofia dos adenoides). ${ }^{5}$

As características da tosse podem igualmente ser relevantes. Uma tosse produtiva sugere doença supurativa (bronquiectasias, disfunção ciliar, fibrose quística, bronquiolite obliterante); uma tosse acessual é frequente na síndrome coqueluchoide; se acompanhada por hemoptise, deve ser considerada a hipótese de bronquiectasias, fibrose quística, abcesso pulmonar, tumores, malformações vasculares, hemossiderose pulmonar, tuberculose, hipertensão pulmonar ou malformações arteriovenosas. A tosse estridulosa aparece na laringomalácia e traqueomalácia ou em massas intra-traqueais. 5,6,24,25,27

Alguns sintomas associados podem ser importantes: sibilância, dermatite atópica, rinite alérgica ou sensibilização a alergénios, exacerbação pelo exercício frio ou exposição a irritantes ou alergénios, na asma; sibilância isolada na hiperreatividade brônquica do lactente, aspiração de corpo estranho, refluxo gastroesofágico, compressão extrínseca, displasia broncopulmonar ou cardiopatia. Uma história de pneumonias recorrentes com má progressão ponderal pode sugerir fibrose quística, imunodeficiência, discinesia ciliar, aspiração crónica, malformações, tuberculose ou doenças intersticiais. A presença de obstrução nasal, rinorreia mucopurulenta ou halitose deve fazer pensar em síndrome da via aérea superior com gotejamento nasal posterior. A cefaleia ocorre em doentes com sinusopatia. Febre recorrente, mal-estar geral, sintomas constitucionais, febre e emagrecimento podem ocorrer na tuberculose. Regurgitação ou asfixia associada a alimentação sugerem síndromes aspirativas. ${ }^{5,6,24,25,27}$

É sempre importante procurar sintomas e sinais de alarme (início neonatal, tosse com alimentação, tosse

TABELA 1. Diagnóstico diferencial de causas específicas de tosse crónica em idade pediátrica.

TOSSE CRÓNICA NA CRIANÇA SAUDÁVEL

- Infeções respiratórias de repetição

- Bronquite bacteriana persistente

- Síndrome de via aérea superior com gotejamento posterior

- Equivalente asmático

- Refluxo gastroesofágico

- Tosse psicogénica

- Tosse irritativa (tabaco, poluentes)

\section{TOSSE CRÓNICA EM CRIANÇAS COM DOENÇA PULMONAR}

- Doenças supurativas: fibrose quística, bronquiectasias, doença pulmonar crónica

- Imunodeficiências

- Síndromes aspirativas

- Aspiração de corpo estranho

- Infeções: Mycoplasma pneumoniae; Chlamydia spp, tuberculose, pneumonia

- Anomalias congénitas: fístula traqueo-esofágica, anel vascular, malformações da via aérea, doenças neuromusculares 
supurativa com expetoração, início brusco, sudorese noturna, perda de peso, hipocratismo) e inquirir sobre antecedentes familiares e pessoais, medicação e exposição ambiental (tabaco, infantário, animais, irritantes). 5,6,25,27

Reconhecer a tosse psicogénica e outros transtornos funcionais como a disfunção das cordas vocais, é importante nos doentes pediátricos, já que o seu diagnóstico é difícil, sendo catalogados frequentemente como asma ou síndrome das vias aéreas superiores. A tosse psicogénica inicia-se com frequência após uma infeção respiratória superior em que se perpetua uma tosse seca, rude, repetitiva, em "grasnado", que surge intermitentemente durante o dia e desaparece quando a criança se distrai ou durante o sono. A tosse psicogénica piora com a atenção dispensada pelos pais e professores preocupados, mas a criança demonstra uma surpreendente indiferença. O diagnóstico é de exclusão.5,6,24,25,27-30

Os exames devem ser solicitados de forma hierarquizada e de acordo com a suspeita clínica. Incluem exames imagiológicos, laboratoriais, testes cutâneos alergológicos, intradermorreação, provas de função respiratória, phmetria, broncofibroscopia e as suas técnicas subsidiárias (biópsia, lavado bronco-alveolar). 5,9-13,16-19,23-25,31 A avaliação complementar exaustiva da criança com tosse sai do âmbito deste artigo.

\section{TRATAMENTO DA TOSSE CRÓNICA}

O tratamento da tosse crónica deve ser etiológico e iniciado após uma avaliação etiológica exaustiva e racional, de acordo com os protocolos de prática clínica mais adequados. A intervenção sobre o meio ambiente (evicção de tabaco e poluentes, alergénios, etc.) é essencial, pelo que não deve ser negligenciada. 6,19,24,28,31

Pela sua frequência, há quatro situações de tosse crónica em idade pediátrica nas quais o diagnóstico pode necessitar de meios sofisticados, dispendiosos ou cruentos. Se houver suspeita clínica, pode ser instituída terapêutica empírica: asma brônquica (presumível responsável por $10 \%$ a $25 \%$ dos casos), ${ }^{31,32}$ rinorreia posterior (20\% a 30\%), 5,6,33-35 refluxo gastroesofágico (5\% a 10\% ${ }^{36,37}$ e bronquite bacteriana persistente ou outra doença infeciosa (25\% a 40\%). ${ }^{36-43}$

ASMA: pode iniciar-se com tosse isolada, seca e recorrente, por vezes noturna. Habitualmente, nalgum período da sua evolução, há referência a sibilância. As características da tosse, persistência da sibilância e provas de função respiratória orientam o diagnóstico. A terapêutica empírica da crise inclui salbutamol e brometo de ipratrópio. Se houver melhoria dos sintomas, é legítimo iniciar um curso de corticoterapia inalada e/ou utilizar modificadores orais dos leucotrienos. Não há atualmente evidência favorável a esta atitude terapêutica da tosse crónica inespecífica atribuída empiricamente a etiologia asmática. ${ }^{44-46}$

RINITE/RINORREIA POSTERIOR CRÓNICA: a tosse ocorre por estimulação mecânica do ramo aferente por secreções descendentes da nasofaringe e dos seios perinasais (hipertrofia dos adenoides na idade pré-escolar, rinite alérgica e sinusite na criança mais velha e adolescente). ${ }^{33-35}$ Para alívio dos sintomas, existem sistemas de humidificação e lavagem das fossas nasais, descongestionantes nasais, corticoides tópicos e anti-histamínicos sistémicos. A lavagem nasal deve ser suave e efetuada com solutos salinos isotónicos ou hipertónicos, seguida de aspiração nasal. ${ }^{5,33-35}$ Os descongestionantes nasais atuam por vasoconstrição da mucosa nasal, com diminuição da inflamação e da hipersecreção. Uma vez que são agonistas alfa-adrenérgicos, podem causar hipertensão arterial, taquicardia e glaucoma. Existem diversos fármacos para administração tópica quer isolados (fenilefrina, oximetazolina e tramazolina) ou, no caso da pseudo-efedrina, em associação com anti-histamínicos. Estes diminuem igualmente a produção de muco nasal, bloqueando os recetores de histamina H1 da mucosa. Desta forma, diminuem o edema e as secreções, e têm algum efeito sedativo, principalmente os de geração mais antiga. São comercializados, no nosso país, os seguintes fármacos em formulação pediátrica: clemastina, hidroxizina, dimetideno, oxatomida, cetirizina, levocetirizina, loradatina, desloratadina. ${ }^{33-35}$

Os corticoides tópicos não demonstraram eficácia na terapêutica empírica da tosse. Quanto aos anti-histamínicos, de acordo com estudos randomizados, há um estudo favorável a cetirizina. ${ }^{47}$

A observação por Otorrinolaringologia, para eventual avaliação de indicação cirúrgica, é igualmente útil.

REFLUXO GASTROESOFÁGICO: o refluxo não causa habitualmente tosse crónica isolada, associando-se esta, em regra, a alterações da deglutição, alimentação ou a regurgitação. ${ }^{36,37} \mathrm{~A}$ ação irritante que as micro-gotículas provenientes do estômago têm nas vias respiratórias pode ser uma causa importante de tosse em crianças pequenas. $O$ diagnóstico é feito por phmetria de 24 horas, eventualmente coadjuvada por impedanciometria, quando se suspeita de refluxo não ácido. Uma vez que estes exames são invasivos e podem não estar disponíveis, é legítimo, nalguns casos, iniciar terapêutica empírica. Nesse contexto, têm sido estudados procinéticos 
(domperidona e metoclopramida) e inibidores da bomba de protões (esomeprazole). Estudos randomizados e controlados não demonstraram qualquer efeito benéfico de nenhum destes fármacos na terapêutica da tosse crónica inespecífica em pediatria. ${ }^{36}$

INFEÇÃO: a tosse crónica pode ocorrer em situações infeciosas (sinusite, adenoidite, pneumonia atípica, tosse convulsa ou bronquite bacteriana prolongada) de diagnóstico etiológico habitualmente difícil. Será, assim, defensável administrar antibioticoterapia empírica nalguns doentes em que esses diagnósticos sejam suspeitos. $5,6,12,17,23,39-43$

Um curso de beta-lactâmicos com inibidores de beta- lactamases durante 2 semanas é adequado a infeções respiratórias altas com rinorreia posterior, como a adenoidite e rinossinusite, em que Streptococcus pneumoniae, Haemophilus influenzae, Moraxella catarrhalis ou Staphylococcus aureus possam estar envolvidos. 5,6,35,43

Recentemente, foi descrita uma entidade infeciosa do aparelho respiratório inferior, a bronquite bacteriana persistente (protracted bacterial bronchitis), que se caracteriza por tosse arrastada, habitualmente por mais de 4 semanas, sem febre nem sibilância, com padrão radiográfico inespecífico, e em que são excluídas outras causas. ${ }^{39-42} \mathrm{O}$ diagnóstico definitivo é feito por broncofibroscopia e lavado broncoalveolar, com observação de secreções purulentas, e identificação frequente de Haemophilus influenzae não tipável, S. aureus, S. pneumoniae ou M. catarrhalis, por vezes em associação. ${ }^{39-42}$ Na prática clínica pode ser justificável, nestes doentes, antes da broncofibroscopia, efetuar antibioticoterapia empírica, com amoxicilina/ácido clavulânico, durante um período de 3 a 4 semanas. Esta prova terapêutica, se não for eficaz, deverá ser seguida de uma investigação etiológica mais alargada. Alguns pacientes com bronquite bacteriana prolongada recorrente necessitam de ciclos largos e repetidos de antibióticos, tendo até sido sugerido por alguns autores a possibilidade de fazer antibióticos inalados. $^{39-42}$

Em crianças de idade escolar e adolescentes com tosse crónica, por vezes com contexto epidemiológico positivo e radiografia do tórax com padrão intersticial hilífugo, é frequentemente admitida a hipótese diagnóstica de pneumonia atípica. Uma vez que o diagnóstico etiológico é demorado e nem sempre disponível, é frequentemente iniciado um curso terapêutico com macrólidos. A tosse convulsa é também frequente entre nós, sendo que nem sempre tem as características clássicas. Devem ser sempre feitas as pesquisas diretas ou serológicas adequadas. .,6,48 $^{-10}$

Em relação à evidência científica, existe na literatura uma meta-análise de três estudos controlados randomizados em idade pediátrica, que demonstrou que antibioticoterapia empírica é superior a placebo em casos de adenoidite, bronquite bacteriana crónica, tosse convulsa e pneumonia atípica. Os autores comentam que os meios de diagnóstico etiológico são hoje em dia ainda pouco conclusivos, devendo ser melhorados. ${ }^{48}$

Em suma, se o doente está bem e o impacto da tosse é moderado, recomenda-se um período de observação sem realização de exames até às 6 a 8 semanas. Se for decidido fazer uma prova terapêutica, esta é empírica e baseia-se em recomendações de peritos, dada a pouca consistência de estudos randomizados controlados na população pediátrica. Pode ser feita corticoterapia inalada durante 2 a 12 semanas nalguns casos de tosse seca, que será retirada se não houver resposta. Nos casos de tosse produtiva inespecífica, pode ser tentado um curso de terapêutica com amoxicilina/ácido clavulânico durante 2 a 4 semanas. Se se admitir a presença de rinite alérgica ou do refluxo gastroesofágico em crianças com tosse isolada, pode ser justificável um período empírico de anti-histamínicos ou inibidores da bomba de protões.

\section{TERAPÊUTICA SINTOMÁTICA DA TOSSE}

Muitas famílias e crianças com tosse arrastada inespecífica, em que não se atingiu ainda um diagnóstico etiológico, sofrem com esse sintoma (exaustão, dificuldade alimentar, diminuição global da qualidade de vida).,5-9 A utilização de fármacos moduladores da tosse deve ser ponderada, em doentes selecionados, de idade superior a dois anos, por períodos curtos, e integrado num plano de investigação etiológica, com possibilidade de reavaliações adequadas da situação.,

Encontram-se disponíveis inúmeros fármacos e dispositivos terapêuticos que reivindicam efeitos benéficos sobre a tosse, e movimentam um volume de negócios muito lucrativo em todo o Mundo. 5,6,16,18,20-23,49-52 Os fármacos disponíveis têm habitualmente baixa segurança, efeitos acessórios significativos e podem atrasar a avaliação adequada do doente. ${ }^{49-51}$

Há quatro grupos de fármacos disponíveis para a terapêutica sintomática da tosse: Antitússicos de efeito central (opiáceos e não opiáceos), antitússicos de ação periférica, demulcentes e mucolíticos., 
Os antitússicos de ação central atuam no sistema nervoso central, diminuindo o reflexo de tosse. Não são recomendados abaixo dos 2 anos de idade. Podem ser usados em períodos curtos e com monitorização sintomática e de efeitos secundários.

Em Portugal existem os seguintes fármacos ${ }^{53}$ :

OPIÁCEOS: codeína, comercializada isoladamente ou integrando associações com antitússicos de ação periférica, e dextrometorfano (disponível em diversas associações).

ANTITÚSSICOS CENTRAIS NÃO OPIÁCEOS: hidrato de cloral, butamirato e o grupo dos anti-histamínicos com efeito sedativo mais fortes, como a difenidramina e fenoripida.

Em geral, os antitússicos de ação central mascaram a causa da tosse e podem ter efeitos secundários importantes, principalmente os opiáceos (depressão respiratória, náuseas, sonolência, ataxia, dependência, alterações do comportamento, alucinações, vómitos, obstipação, exantema, edema, prurido). Devem ser evitados em asmáticos ou na suspeita de apneia obstrutiva do sono. $5,6,11-13,18,20,24,49-51,54$

A utilização deste grupo de fármacos deve ser judiciosa, em famílias e doentes muito selecionados, com quadros muito incapacitantes e quando é possível vigilância e reavaliação cuidadosa.

Os antitússicos de ação periférica derivam dos anestésicos locais, e ligam-se aos recetores da tosse, atenuando a sua resposta aos estímulos. Não são recomendados abaixo dos 2 anos de idade por terem alguns efeitos centrais associados. Em Portugal, estão disponíveis atualmente a dropropizina, a levodropropizina e a oxolamina. ${ }^{53}$ A sua eficácia é, em geral, reduzida, e podem atrasar o diagnóstico etiológico.

Os demulcentes são substâncias derivadas da sacarose, que atuam pela estimulação da salivação e deglutição, revestindo os recetores de tosse da orofaringe, aumentando o seu limiar de resposta. Na maioria dos casos, são obtidos a partir do mel, de extratos vegetais ou edulcorantes artificiais que são também excipientes de vários xaropes. Alguns incluem substâncias voláteis com efeito na mucosa nasal. Têm efeitos modestos, mas perfis de segurança favoráveis. São exemplos de demulcentes as suspensões de essência de eucalipto, anis, folhas de hera e a maioria dos xaropes caseiros (mel, cenoura, limão, hortelã, cebola, entre outros). ${ }^{20,49-53}$ Uma meta-análise de três estudos controlados randomizados em idade pediátrica sobre o efeito do mel na terapêutica sintomática da tosse na criança revelou que este tinha efeitos superiores ao placebo e sobreponível a dextromorfano. Os efeitos secundários gastrointestinais foram raros e ligeiros. ${ }^{21,52}$

Os expetorantes e mucolíticos atuam por modificação das características reológicas do muco respiratório ou estimulação da sua produção. No primeiro grupo incluem-se a acetilcisteína, ambroxol, bromexina e carbocisteína. No segundo encontra-se disponível no mercado português a guainfenesina, que atua por estimulação reflexa de produção de muco respiratório quando o medicamento chega ao estômago. Existem também xaropes que contêm substâncias voláteis que estimulam diretamente a produção de muco quando contactam com a mucosa do aparelho respiratório: eucalipto, mentol, álcool e cânfora. ${ }^{49-53}$

Estes fármacos têm indicação bastante restrita. Somente os pacientes com secreção anormalmente espessa devem utilizá-los, já que o seu uso no muco de consistência normal o torna muito fluido e dificulta o funcionamento ciliar e a eliminação do muco em excesso. 5,6

Em suma, a evidência científica que sustenta a utilização de xaropes para a tosse é muito escassa. Devem-se evitar associações, mas desprovidas de lógica, mas de venda livre (antitússicos com mucolíticos, sedativos com expetorantes), bem como produtos com doses inadequadas ou sub-terapêuticas. Os estudos referem a elevada frequência e gravidade dos efeitos secundários dos antitússicos de ação central. ${ }^{54}$

Em relação à homeopatia, ou produtos vendidos em ervanárias, há a referir a completa ausência de evidência científica, nomeadamente através de estudos randomizados duplamente cegos ou quaisquer outros estudos credíveis. É de destacar igualmente a imprevisibilidade de tipo e gravidade dos efeitos acessórios possíveis. 5,6

\section{CONCLUSÃO}

A tosse persistente é um dos motivos mais frequentes de consulta e episódios de urgência em idade pediátrica. Trata-se de um sintoma inespecífico, presente em muitas situações de gravidade variável. Após uma infeção respiratória viral infantil, a tosse pode persistir por períodos de até 8 semanas.

Ao ajudar a expelir substâncias nocivas, a tosse tem um papel protetor das vias aéreas. Na verdade, na ausência de tosse eficaz, as complicações são em geral mais graves e com pior prognóstico. 
A terapêutica das situações que cursam com tosse persistente deve ser, sempre que possível, etiológica, após uma avaliação racional. Na ausência de outros sintomas acompanhantes, as causas mais frequentes de tosse persistente são: síndrome pós-infeção viral, infeção, rinorreia posterior, asma ou refluxo gastroesofágico. Nalgumas dessas crianças e adolescentes pode ser útil efetuar uma prova terapêutica com anti-histamínicos, broncodilatadores, inibidores da bomba de protões ou antibióticos.

A terapêutica sintomática pura da tosse pode ter o seu lugar em doentes selecionados (nunca abaixo dos dois anos de idade), por períodos curtos, com acompanhamento médico e integrada num plano de avaliação diagnóstica. A humidificação das secreções e a lavagem das fossas nasais constituam a ser a terapêutica sintomática mais eficaz e segura. $\bigcirc$ uso de vasoconstritores nasais, demulcentes, mucolíticos e antitússicos centrais ou periféricos pode ser útil. Os xaropes para a tosse têm baixa eficácia e segurança, efeitos acessórios relevantes e podem atrasar o diagnóstico. É preferível usar fármacos em formulação isolada e evitar associações. A tranquilização da família é fundamental, bem como o controlo ambiental, nomeadamente a evicção do fumo de tabaco, passivo ou ativo, e de outros contaminantes atmosféricos.

CONFLITOS DE INTERESSE: Os autores declaram não ter qualquer conflito de interesse na realização do presente trabalho.

FONTES DE FINANCIAMENTO: Não houve qualquer fonte de financiamento na realização do presente trabalho.

CONFLICTS OF INTEREST: The authors declare that they have no conflicts of interest.

FINANCIAL SUPPORT: This work has not received any contribution, grant or scholarship.

\section{REFERÊNCIAS}

1. Chang AB. Cough, cough receptors, and asthma in children. Pediatr Pulmonol. 1999; 28: 59-70.

2. McCool FD, Leith DE. Pathophysiology of cough. Clin Chest Med. 1987; 8: 189-95.

3. Shann F. How often do children cough. Lancet. 1996; 348:699700.

4. Munyard P, Bush A. How much coughing is normal. Arch Dis Child. 1996; 74: 531-4.

5. Bergamini M, Kantar A, Cutrera R, Interest Group IPC. Analysis of the literature on chronic cough in children. Open Respir Med J. 2017; 11:1-9.

6. Lamas A, Ruiz de Valbuena M, Maíz L. Tos en el niño. Arch Bronconeumol. 2014; 50: 294-300.

7. Marchant JM, Newcombe PA, Juniper EF, Sheffield JK, Stathis
SL, Chang AB. What is the burden of chronic cough for families. Chest. 2008; 134: 303-9.

8. French CL, Irwin RS, Curley FJ, Krikorian CJ. Impact of chronic cough on quality of life. Arch Intern Med. 1998; 158: 1657-61.

9. Chang AB, Robertson CF, van Asperen PP, Glasgow NJ, Masters IB, Teoh L, et al. A cough algorithm for chronic cough in children: A multicenter, randomized controlled study. Pediatrics. 2013; 131: e1576-83.

10. McCallum GB, Bailey EL, Morris PS, Chang AB. Clinical pathways for chronic cough in children. Cochrane Database Syst Rev. 2014;9: CD006595.

11. Irwin RS, Baumann MH, Bolser DC, Boulet LP, Braman SS, Brighling CE, et al. Diagnosis and management of cough executive summary: ACCP evidence-based clinical practice guidelines. Chest. 2006; 129 Suppl 1: 1-23.

12. Shields MD, Bush A, Everard ML, McKenzie S, Primhak R, British Thoracic Society Cough Guideline Group. BTS guidelines: Recommendations for the assessment and management of cough in children. Thorax. 2008; 63 Suppl 3: 1-15.

13. Gibson PG, Chang AB, Glasgow NJ, Holmes PW, Katelaris P, Kemp AS, et al. CICADA: Cough in Children and Adults: Diagnosis and Assessment. Australian Cough Guidelines summary statement. Med J Aust. 2010; 192: 265-71.

14. Martins S, Moura MC, Neves AM, Trindade JC. Tosse em Pediatria. Rev Port Pneumol. 2008; 14: 517-26.

15. Chang AB, Landau LI, van Asperen PP, Glasgow NJ, Robertson CF, Marchant JM, et al. Cough in children: Definitions and clinical evaluation. Med J Aust. 2006; 184: 398-403.

16. Goldsobel AB, Chipps BE. Cough in the pediatric population. J Pediatr. 2010; 156: 352-8.

17. Brodlie M, Graham C, McKean MC. Childhood cough. BMJ. 2012; 344: e1177.

18. Chang AB. Pediatric cough: Children are not miniature adults. Lung. 2010; 188 Suppl 1: 33-40.

19. Chang AB, Berkowitz RG. Cough in the pediatric population. Otolaryngol Clin North Am. 2010; 43: 181-98.

20. Smith SM, Schroeder K, Fahey T. Over-the-counter (OTC) medications for acute cough in children and adults in community settings. Cochrane Database Syst Rev. 2014; 11: CD001831.

21. Oduwole O, Meremikwu MM, Oyo-Ita A, Udoh EE. Honey for acute cough in children. Cochrane Database Syst Rev. 2014; 12: CD007094.

22. Hay AD, Schroeder K, Fahey T. Acute cough in children. BMJ. 2004; 328: 1062.

23. Begic E, Bejic Z, Dobraca A, Hasabegovic E. Productive cough in children and adolescents - view from Primary Care System. Med Arch. 2017; 1: 66-8.

24. Chang AB, Glomb WB. Guidelines for evaluating chronic cough in pediatrics: ACCP evidence-based clinical practice guidelines. Chest. 2006;129 Suppl 1: 260-83.

25. Asilsoy S, Bayram E, Agin H, Apa H, Dan D, GulleS, et al. Evaluation of chronic cough in children. Chest. 2008; 134: 1122-8.

26. Marchant JM, Masters IB, Taylor SM, Cox NC, Seymour GJ, Chang AB. Evaluation and outcome of young children with chronic cough. Chest. 2006; 129: 1132-41.

27. Khoshoo V, Edell D, Mohnot S, Haydel R Jr, Saturno E, Kobernick $A$. Associated factors in children with chronic cough. Chest. 2009; 136: 811-5.

28. Rank MA, Kelkar P, Oppenheimer JJ. Taming chronic cough. Ann Allergy Asthma Immunol. 2007; 98: 305-13. 
29. Ramanuja S, Kelkar P. Habit cough. Ann Allergy Asthma Immunol. 2009; 102: 91-5.

30. Cobeta I, Pacheco A, Mora E. The role of the larynx in chronic cough. Acta Otorrinolaringol Esp. 2013; 64: 363-8.

31. De Jongste JC, Shields MD. Cough. Chronic cough in children. Thorax. 2003; 58: 998-1003.

32. Van Asperen PP. Cough and asthma. Paediatr Respir Rev. 2006;7:26-30.

33. Pratter MR. Chronic upper airway cough syndrome secondary to rhinosinus diseases (previously referred to as postnasal drip syndrome): ACCP evidence based clinical practice guidelines. Chest. 2006; 129 Suppl 1: 63-71.

34. Pacheco A, Cobeta I, Wagner C. Refractory chronic cough: New perspectives in diagnosis and treatment. Arch Bronconeumol. 2013; 49: 151-7.

35. Marchant JM, Masters IB, Taylor SM, Cox NC, Seymour GJ, Chang AB. Utility of signs and symptoms of chronic cough in predicting specific cause in children. Thorax. 2006; 61: 694-8.

36. Chang AB, Lasserson TJ, Gaffney J, Connor FL, Garske LA. Gastro-oesophageal reflux treatment for prolonged non-specific cough in children and adults. Cochrane Database Syst Rev. 2011: CD004823.

37. Irwin RS. Chronic cough due to gastroesophageal reflux disease: ACCP evidence based clinical practice guidelines. Chest. 2006; 129 Suppl 1: 80-94.

38. Paul IM. Therapeutic options for acute cough due to upper respiratory infections in children. Lung. 2012; 190: 41-4.

39. Shields MD, Thavagnanam S. The difficult coughing child: Prolonged acute cough in children. Cough. 2013; 9-11.

40. Craven V, Everard ML. Protracted bacterial bronchitis: Reinventing an old disease. Arch Dis Child. 2013; 98: 72-6.

41. Chang AB, Redding GJ, Everard ML. Chronic wet cough: Protracted bronchitis, chronic suppurative lung disease and bronchiectasis. Pediatr Pulmonol. 2008; 43: 519-31.

42. Donnelly D, Critchlow A, Everard ML. Outcomes in children treated for persistent bacterial bronchitis. Thorax. 2007; 62: 80-4.

43. Hodgson D, Anderson J, Reynolds C, Oborne J, Meakin G, Bailey $\mathrm{H}$, et al. The effects of azithromycin in treatment-resistant cough. A randomized, double-blind, placebo-controlled trial. Chest. 2016; 149: 1052-60.

44. Becker LA, Hom J, Villasis-Keever M, van der Wouden JC. Beta2-agonists for acute cough or a clinical diagnosis of acute bronchitis. Cochrane Database Syst Rev. 2015; 9: CD001726.

45. Tomerak AAT, McGlashan J, Lakhanpaul M, Vyas HHV, McKean MC. Inhaled corticosteroids for non-specific chronic cough in children. Cochrane Database Syst Rev. 2005; 4: CD004231.

46. Chang AB, Winter D, Acworth JP. Leukotriene receptor antagonist for prolonged non-specific cough in children. Cochrane Database Syst Rev. 2006: CD005602.

47. Chang AB, Peake J, McElrea MS. Anti-histamines for prolonged non-specific cough in children. Cochrane Database Syst Rev. 2008; 2: CD005604.

48. Gardiner SJ, Gavranich JB, Chang AB. Antibiotics for community-acquired lower respiratory tract infections secondary to Mycoplasma pneumoniae in children. Cochrane Database Syst Rev. 2015; 1: CD004875.

49. Kuehn BM. FDA: Cold medications risky for young children. JAMA. 2007; 298:1151.

50. Smith SM, Schroeder K, Fahey T. Over-the-counter medications for acute cough in children and adults in ambulatory settings. Cochrane Database Syst Rev. 2008: CD001831.
51. Schaefer MK, Shehab N, Cohen AL, Bunitz DS. Adverse events from cough and cold medications in children. Pediatrics. 2008; 121:783-7.

52. Cohen HA, Rozen J, Kristal H, Laks Y, Berkovitch M, Uziel Y, et al. Effect of honey on nocturnal cough and sleep quality: A double-blind, randomized, placebo controlled study. Pediatrics. 2012; 130: 465-71.

53. Infomed - Base de dados de medicamentos. [Accessed Dec 2017]. Available from: http://app7.infarmed.pt/infomed/lista. php

54. Gardiner SJ, Chang AB, Marchant JM, Petsky HL. Codeine versus placebo for chronic cough in children. Cochrane Database Syst Rev. 2016; 7: CD011914. 